\title{
GIS-Aided Modelling of Two Siberian Reservation Sites
}

\author{
Marina Erunova ${ }^{1,3}$ and Michael Sadovsky ${ }^{1,2}$ \\ ${ }^{1} \mathrm{SFU}, 660041$ Krasnoyarsk, Russia \\ ${ }^{2}$ Institute of computational modelling of SB RAS, \\ Akademgorodok, 660036 Krasnoyarsk, Russia \\ ${ }^{3}$ Krasnoyarsk state agrarian university, 660049 Krasnoyarsk, Mira prosp., 90 \\ \{marina, msad\}@icm.krasn.ru \\ http://icm.krasn.ru
}

\begin{abstract}
Reserved territories seem to be the best reference sites of wildnature, where the long-term observations are carried out. Simulation model of spatially distributed processes of contamination of such reservation is developed, and the dynamics of some pollutants is studied. An issue of the generalized evaluation of an ecological system status is discussed.
\end{abstract}

Keywords: pollution; correlation; analysis; modelling; spatial analysis

\section{Introduction}

Human activities impact heavily various ecological systems, especially at the regions with severe climate, and the impact may be irreversible. Non-ferrous and heavy metals the number one in global pollution (see [1] for details). Mathematical models are the tool to study a dynamics of deteriorated ecosystems. Studying spatially distributed communities, one faces the problem towards the interplay of geography of a site, and the biological features of the inhabitants. A number of landscape-scale models have been developed in attempt to predict a vegetation pattern or other natural resources [2-7].

Russia has a unique experience in wildnature reservation through the establishment of areas (called zapovednik) specially protected by law; special federal agency supervises them. No activity, nut a research is allowed in such areas. The sites play a key rope in understanding and forecasting of the dynamics of global pollution. Here GIS address the complex study of dynamics of physical, geographical and biological processes run at zapovedniks best of all. The studies of protected areas/reservations with GIS tools are not too convenient; some results in that direction see in $[8,9])$. The studies of fully preserved territories located at Russia, in Central Siberia are presented by N.Prechtel $[10,11])$. Here we present the basic solution (developed primarily for Stolby zapovednik, see [1, 17]) to unify and standard GIS based solution to be applicable for any area.

Here we present some results on the life dynamics observed at Tzentral'nosibirskii zapovednik. Basically, we intend: 
1) to reveal the statistical relationship between a forest type and some physical and geographical features of the landscape;

2) to reveal the statistical relationship between a forest type and features of landscape;

3) to reveal and present a pattern of the contamination with some pollutants.

\section{Material and methods}

\subsection{Study area}

Tzentral'nosibirskii State Biospheric Wildnature Reservation (zapovednik) is located approximately $1000 \mathrm{~km}$ north from Krasnoyarsk, occupying two sites on both banks of the river of Yenisei (see Fig. 1), thus preventing the anthropogenic impact on the river ecosystem. Its total area is 10118.49 square kilometres. This is a huge area; the altitude of zapovednik varies from see level to app. 600 meters above. Zapovednik has extended hydrography network containing more than thousand of lakes and watery rivers, and more than 6000 small rivers and springs. It was established in 1985, there are six stationary observatories (they are the check-points, simultaneously), and more than a hundred of temporary observatories located site-wide.

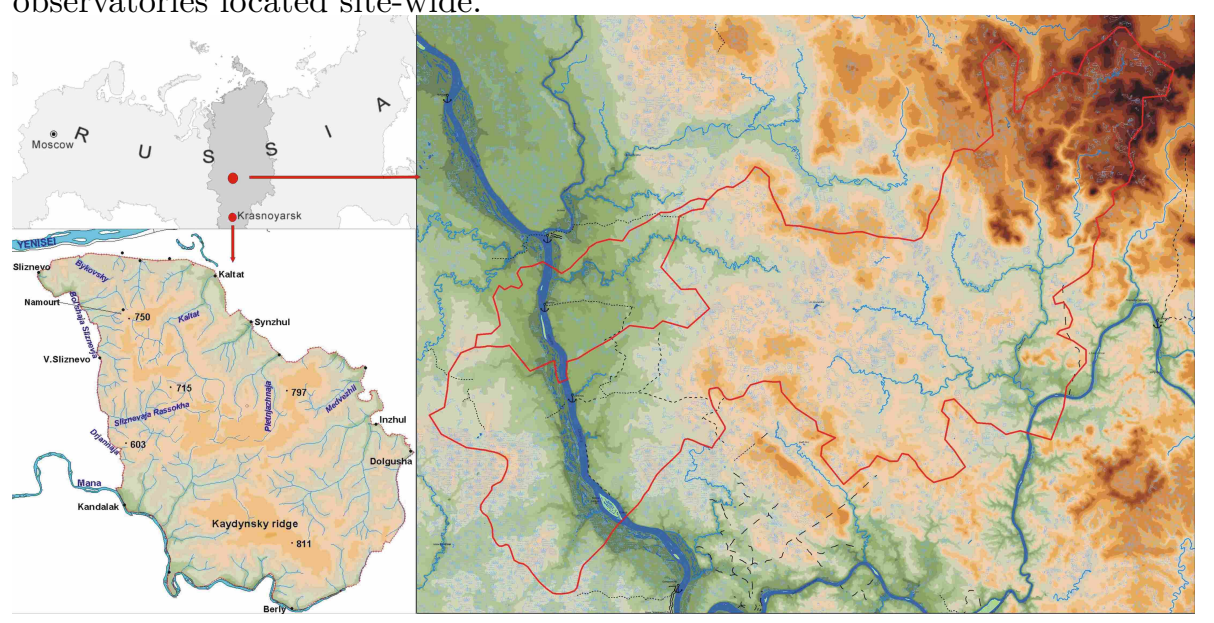

Fig. 1. Location of Siberian zapovedniks at Russia.

\subsection{Data collection description}

GIS-database incorporates relief data, soil type distribution data, river network data, road network data, and the detailed forest estimation data. The forest estimation database specifies forty data fields. All these databases are conveyed in the digital form. 
Tzentral'nosibirskii zapovednik is the perfect reference site, for the purposes of global monitoring of some pollutants, since it exhibits the least possible influence resulted from a human activity. Currently, winter precipitations are monitored. The observatory network is quite complex, since the territory of zapovednik is extended very much. Previously, few anomalies of heavy metals content have been found; hence, the observatories are located rather sporadically, in the areas with low pollutants level. Reciprocally, the observatories are located in more regular manner, at the sites with increased pollutants content, to verify whether the anomaly comes from geographical features, or it results from a human activity.

We traced the concentrations of $\mathrm{Ph}, \mathrm{F}, \mathrm{S}, \mathrm{Cl}, \mathrm{Pb}, \mathrm{Sr}, \mathrm{Al}, \mathrm{Cd}, \mathrm{Fe}, \mathrm{Cu}, \mathrm{Zn}, \mathrm{Cr}$, $\mathrm{Mn}, \mathrm{Ni}, \mathrm{Co}, \mathrm{K}, \mathrm{Na}, \mathrm{Ca}$, and $\mathrm{Mg}$, at winter precipitations. The collected samples were treated as described in our previous paper $[1,16,17]$.

\subsection{GIS-based method}

ArcGIS software package supplied with Spatial Analyst and 3D Analyst modules have been used to debelol digital model of zapovednik, and carry out the spatial data analysis. MapInfo Professional package has been used to convert the data formats. EasyTrace software package was used to digitalize the cartography data on vegetation mapping.

Federal Agency for Cartography and Geodesy provided the primary geographical data of $1 \div 200000$ scale; the vegetation map of $1 \div 50000$ scale was used. Ten individual map-cases were cohered, and data bases were merged. The vegetation map was processed through the scanning and digitalization, and the attributive data were converted from paper sources, namely from the charts of vegetation type description.

The techniques for spatial analysis [15] were used to study geographical features of the site. The following item have been implemented:

- primarily spatial analysis (positioning, object detection via their attributes, computations involving geometry objects of higher level);

- measurements (linear features of polygons, shape measures, distances);

- classification (thematic cartography, neighbourhoods search, filtering, buffers, slopes and aspects);

- statistically defined surfaces (relief digital models, interpolations, grid models);

- spatial distributions (triangulations, lines and polygons distributions, orientation of linear and polygonal objects);

- overlays (selection, mapping of point, linear and polygonal objects).

Thematic maps for the pollutants mentioned above are developed, currently, for winter precipitations. The heavy metal concentrations, as well as some halogens concentrations were used as the input data for soil pollution maps to study the distribution of metals in various compartments of zapovednik. Spatial interpolation of data was carried out with Inverse Distance Weighting (IDW). Grid size of $15 \times 15 \mathrm{~m}^{2}$ was implemented using all the input points available with fixed weight of an observation point. 


\section{Results}

\subsection{Model of zapovednik}

Tzentral'nosibirskii zapovednik digital model differs, to some extent, from the similar one implemented for Stolby zapovednik [1]. First of all, no spatial dynamics based on GIS solution has been developed, yet. The shortage results from a lack of long-time observations, since the zapovednik has been founded at 1985 . The simulation model consists of the digital layers, and the data from numerous databases attributed to the points, in those layers. All the points in the layers are categorized for those incorporating the observations properly located at the layers, and interpolated ones, with special respect to relief peculiarities.

The digital model of zapovednik has the following layers: altitude isolines, reservation borders, rock pillars, river network (both polygonal, and linear objects), springs, forest roads, walking paths, check-points, forestry borders, compartment lines, elevation points, forest estimation, soils, and others.

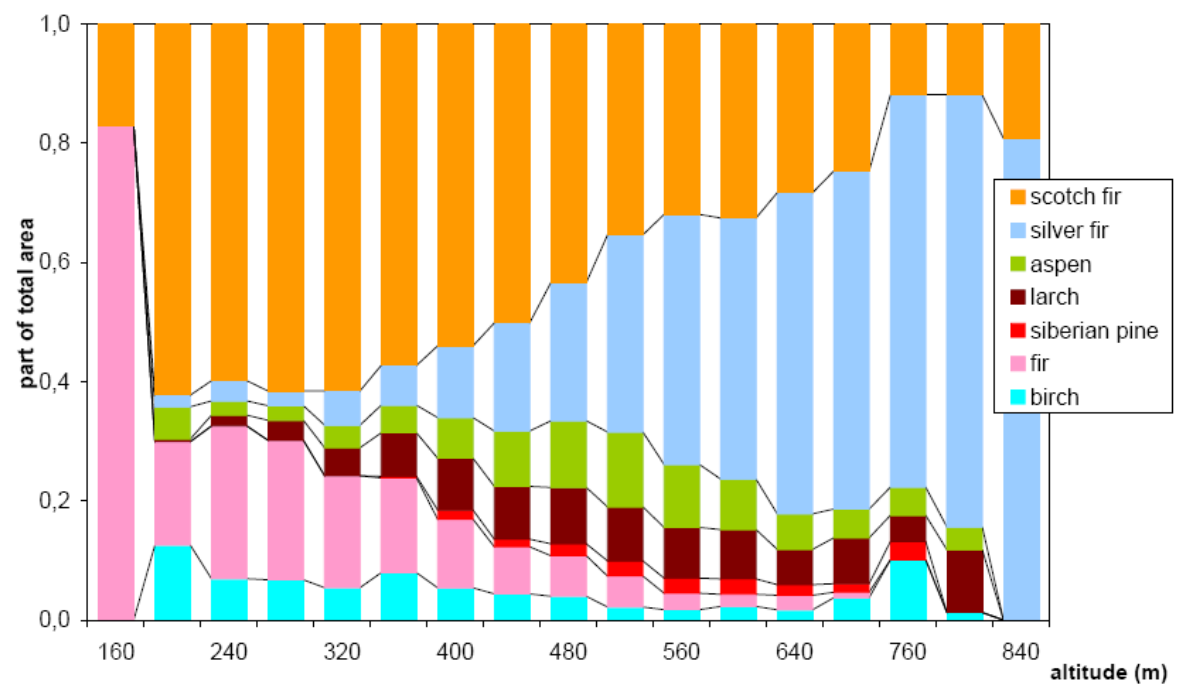

Fig. 2. Distribution of types of forestry over the altitude, at "Stolby" zapovednik, in terms of a portion of total area.

Unlike for the digital model of "Stolby" zapovednik, this model contains four separate layer of the forests; it results from the huge geographical extensions of "Tzentral'nosibirskii" zapovednik. Each layer of the forests corresponds entirely to a forestry. These for layers could not be merged into a single one, since they are too large. Nonetheless, the basic principle of the digital model implementation (that is the basin based implementation) makes no problem with the data exploration over these four separate layers. It should be also said, that the soil layers are obtained from a soil studies of the territory, but from the forest type description; thus, a soil layer is indeed a component of the afforestation inspection of a forest layer. The inspection has been carried out in 1990 . 
Also, river layer differs from the similar one developed for "Stolby" zapovednik. Since the geographical map and vegetation map exhibit different scale, the river layer was implemented in two copies, differing in details, with two scales: $1 \div 200000$ and $1 \div 50000$. A choice of a specific river network layer is determined by the task to be done.

\subsection{Spatial analysis of physics geography data}

The analysis of distribution of forest types with respect to an altitude yields a prevalence of pine vegetation at almost any height (see Fig. 2). The altitude vegetation distribution pattern is rather irregular, exhibiting significant variations in landscape features (slopes, mountain ridges, etc.). Fig. 2 shows percentage of area of the reservation in dependence on the height. Thus, Fig. 3 shows the distribution of individual vegetation types with respect to a height indicating the absolute area measure occupied by a specific vegetation type at the given height. For example, pines occur mainly at the places located from 300 meters to 700 meters in height, with total occupation area up to $25 \mathrm{~km}^{2}$. The maximal area of pine occupation is observed for the altitude ranging from 500 meters to 520 meters. Similar pattern of a vegetation type distribution could be obtained for other species.

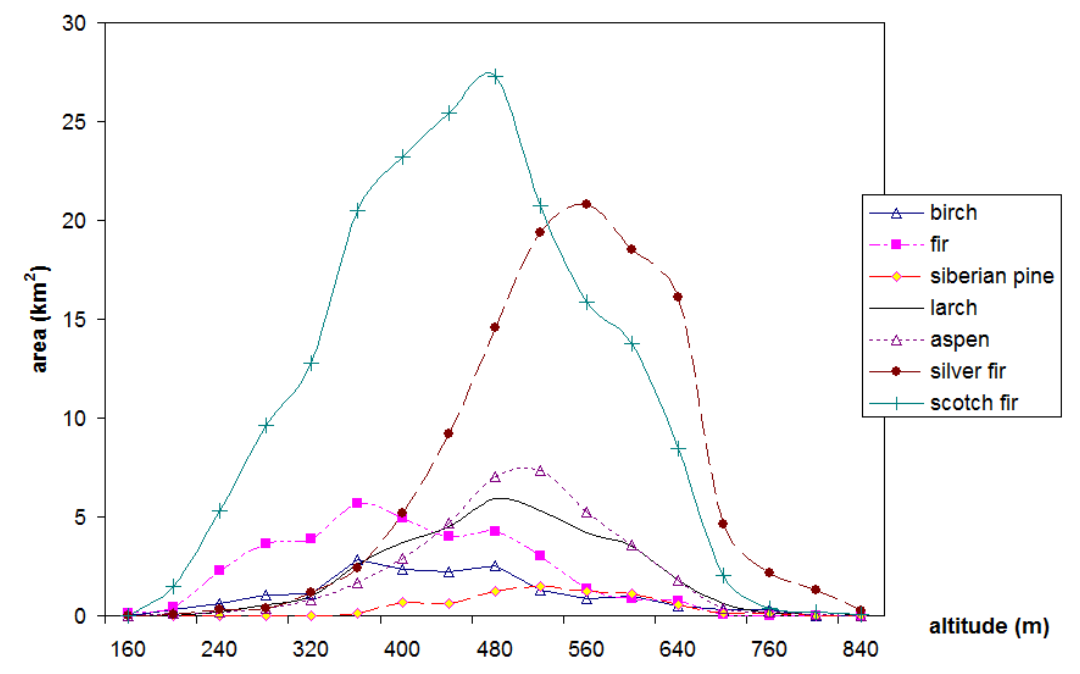

Fig. 3. Distribution of types of forestry over the altitude, at "Stolby" zapovednik.

Fig. 3 represents the area of each vegetation type as a portion of the entire reservation area. This chart reveals the part of each vegetation type occupying the specific height. In contrast to Fig. 2, this figure clearly presents the contribution of various forest species, within a specific height layer of the site. Besides, we have verified the vegetation map of "Stolby" state reservation, with particular respect to the succession of aspen for fir, for the last years. Large scale vegetation 
map $(1 \div 25000)$ of the reservation presents the classification of flora, identifying 70 groups of forest types gathered into 21 series. This map mainly aims to figure out a spatial arrangement of groups and series of the types of biogeocenoses into basic structural entities: so called zone altitude complexes (ZAC).

\subsection{Pollutant distribution pattern}

Table 1. 1: element; 2: watershed of Osinovka river; 3: watershed of Upper Lebedjanka river; 4: watershed of Inzyrevka river; 5: watershed of Great Komsa river; 6: generalized pollution level observed at "Stolby" Reservation; 7: the city of Krasnoyarsk, observations carried out over the district with the most favourable environmental conditions.

\begin{tabular}{|l|r|r|r|r|r|r|}
\hline \multicolumn{1}{|c|}{ conditions. } & 2 & 3 & 4 & 5 & 6 & 7 \\
\hline $\mathrm{Ph}$ & 5.0 & 5.6 & 4.9 & 4.7 & 5.5 & 8.0 \\
\hline $\mathrm{F}, \times 10^{-2}$ & 1 & 1 & 1 & 1 & 1 & 28 \\
\hline $\mathrm{S}$ & 0.10 & 0.29 & 0.10 & 0.10 & 0.67 & 4.42 \\
\hline $\mathrm{Cl}$ & 0.150 & 0.150 & 0.150 & 0.150 & 0.940 & 1.890 \\
\hline $\mathrm{Pb}, \times 10^{-4}$ & 7 & 7 & 4 & 9 & 28 & 42 \\
\hline $\mathrm{Sr}, \times 10^{-3}$ & 4 & 7 & 4 & 4 & 4 & 102.4 \\
\hline $\mathrm{Al}$ & 0.015 & 0.030 & 0.015 & 0.015 & 0.015 & 1.230 \\
\hline $\mathrm{Cd}$ & \multicolumn{5}{|c|}{$9 \cdot 10^{-5}$} \\
\hline $\mathrm{Fe}, \times 10^{-1}$ & 0.10 & 0.16 & 0.16 & 0.24 & 0.44 & 6.53 \\
\hline $\mathrm{Cu}, \times 10^{-3}$ & 1.7 & 2.4 & 0.9 & 1.7 & 2.9 & 3.4 \\
\hline $\mathrm{Zn}, \times 10^{-2}$ & 0.83 & 3.28 & 1.01 & 0.93 & 0.89 & 17.2 \\
\hline $\mathrm{Cr}, \times 10^{-5}$ & 5 & 5 & 5 & 5 & 60 & 260 \\
\hline $\mathrm{Mn}, \times 10^{-3}$ & 3.7 & 5.2 & 3.9 & 2.7 & $\mathrm{~N} / \mathrm{A}$ & $\mathrm{N} / \mathrm{A}$ \\
\hline $\mathrm{Ni}, \times 10^{-4}$ & 4 & 15 & 2 & 4 & $\mathrm{~N} / \mathrm{A}$ & $\mathrm{N} / \mathrm{A}$ \\
\hline $\mathrm{Co}, \times 10^{-4}$ & 1 & 2 & 1 & 1 & $\mathrm{~N} / \mathrm{A}$ & $\mathrm{N} / \mathrm{A}$ \\
\hline $\mathrm{K}$ & 1.1 & 1.6 & 0.7 & 0.9 & $\mathrm{~N} / \mathrm{A}$ & $\mathrm{N} / \mathrm{A}$ \\
\hline $\mathrm{Na}$ & 0.5 & 2.5 & 0.3 & 0.4 & $\mathrm{~N} / \mathrm{A}$ & $\mathrm{N} / \mathrm{A}$ \\
\hline $\mathrm{Ca}$ & 0.20 & 0.56 & 0.29 & 0.14 & $\mathrm{~N} / \mathrm{A}$ & $\mathrm{N} / \mathrm{A}$ \\
\hline $\mathrm{Mg}$ & 0.02 & 0.07 & 0.04 & 0.02 & $\mathrm{~N} / \mathrm{A}$ & $\mathrm{N} / \mathrm{A}$ \\
\hline
\end{tabular}

background level (see Table 1 ).
"Tzentral'nosibirskii" zapovednik is located very far from any sources of industrial pollution, so it was proposed to cancel environmental monitoring similar to that one carried out at "Stolby" zapovednik. Pollution level data observed at "Stolby" zapovednik had gaps, for some specific pollutants [1]. On the contrary, pollution level of the pollutants to be observed at "Tzentral'nosibirskii" zapovednik was supposed to be equal to the background one. We traced the level of those pollutants at "Tzentral'nosibirskii" zapovednik, trying to heal the gaps mentioned above. In 2006, a pilot screening research has been carried out, at four basins located alongside Yenisei river. The motivation behind such screening was the hypothesis towards a lack of global pollution to be observed at these point.

Surprisingly, the screening observations had shown an excess of some pollutants over the

\subsection{Modelling of pollutant distribution}

A distribution of chemical pollutants, as well as their migration is affected with numerous complex factors. The behaviour of pollutants could hardly be described and present in simple figures; the point is that some pollutants are tended to a reasonably stable bunching, while others are not. Thus, one can quite precisely foresee the behaviour of some pollutants observing some of them considered to 
be very indicative. Here we figure out two patterns of pollutant distribution: the former is a general one, and the latter is $\mathrm{Zn}$.

It is a common practice to show the results of monitoring of global pollutants in generalized index, in site of the fact that this latter may loose some (maybe, important) details. To address the problem, we developed GIS-based model producing such index:

$$
K_{c}=\frac{C}{C_{b}},
$$

where $K_{c}$ is the concentration factor of a chemical element, $C$ is the real content of that latter, and $C_{b}$ is the background content of the element. $K_{c}$ indicates an excess of the element content over an averaged background level of that latter determined over a territory. The reference sites are expected to show the pollution figures minimally affected from outside.

Quite often, compartments of an ecosystem are poisoned with several elements. Here the total contamination index could be derived representing an effect of a group of elements. This factor is determined for all elements detected within a sample attributed to a site where the sampling has been done; both the formula for the factor, and its value are established legally. Thus, the total pollution index $Z_{c}$ is defined as follows:

$$
Z_{c}=\sum_{j=1}^{n} K_{c}^{(j)}-(n-1)
$$

where $K_{c}^{(j)}$ is the concentration index of $j$-th pollutant, and $n$ is the number of pollutants.

Basically, the idea to make a generalized index stands of the concept of maximum permissible concentration (MPC). The point is that MPC methodology fails to take into account the specific features of a region, or a specificity of a pollutant impact on environment, etc. This discrepancy was broken through due to the model implementation, that changes a background level values of pollutants in compartments for clarkes. Besides, the background indices for fluorine and heavy metals are not available for the site.

\subsection{Spatial analysis of zinc distribution}

To begin with, we start from the data on zinc distribution. Zinc is motile element at acid and low-acid soils, with moderate phytotoxicity. The growth of concentration of zinc yields a suppression of vegetation [3]. Zinc is mainly delivered to soil with industrial wastes from non-ferrous metallurgy, paintwork material industry, galvanism sewage and slugs of municipal sewage treatment facility.

The analysis of zinc distribution at the substrate (see Fig 4, C) shows that zinc content exceeds the background level, in general. There is a single site close to Synzhul check-point where the concentration is less than $40 \mathrm{mg} / \mathrm{kg}$. Zinc contaminates the reservation, at most; the content ranges from 40 to $80 \mathrm{mg}$ per $\mathrm{kg}$, twice exceeding the background level. The area located closely to Kaltat 

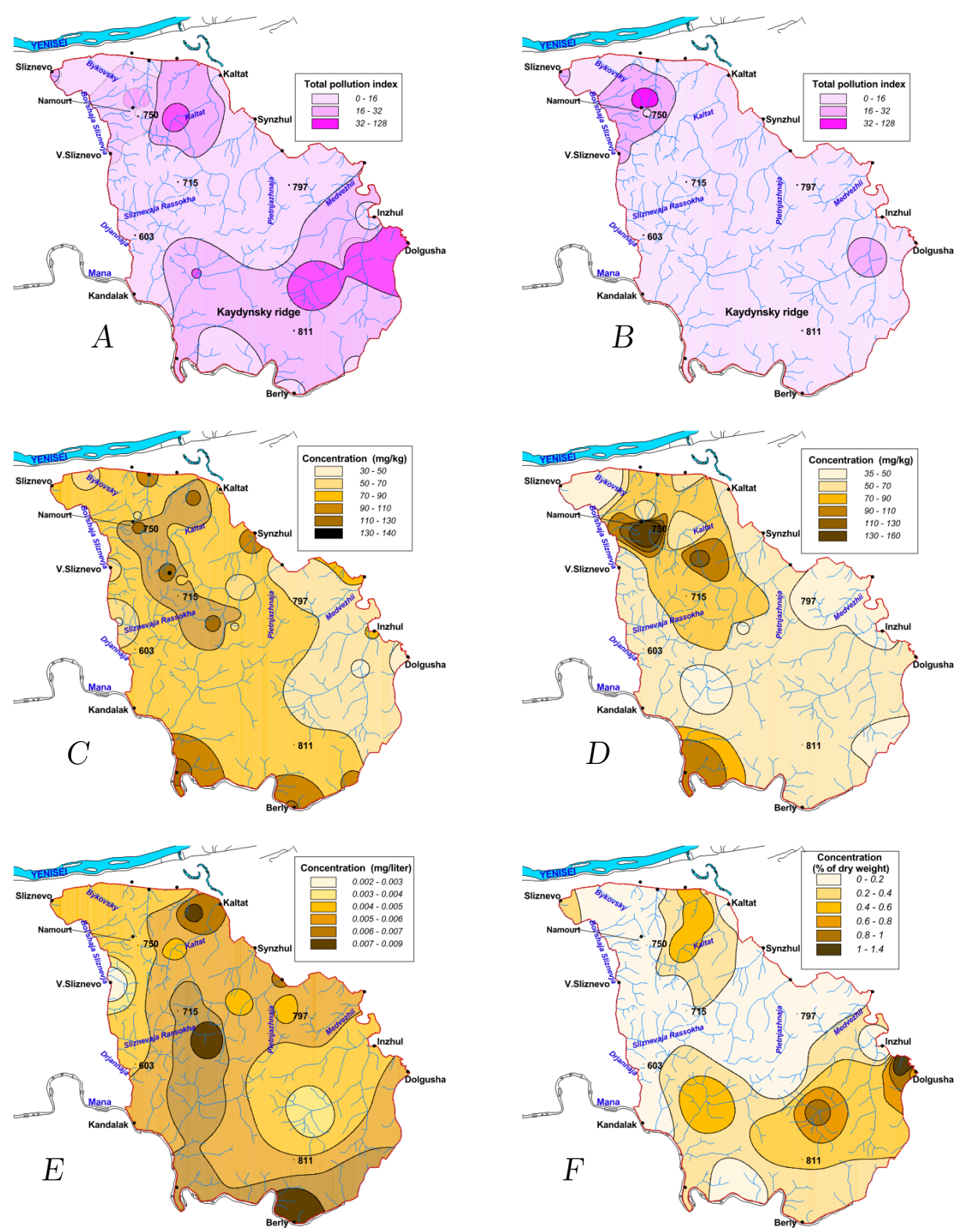

Fig. 4. Pollution patterns for general pollution (in substrate $(A)$ and in soil $(B)$, and zinc pollution (see details in text). 
river, Sliznevaja river, Sliznevaja Rassokha river, and Drjannaja river, as well as close to Bykovsky spring are exposed to high zinc content (more than $80 \mathrm{mg} / \mathrm{kg}$ ).

Zinc distribution in soil (see Fig 4, D) differs from that former in substrate. Basically, zinc content is close to the background level; this latter is equal to $51 \mathrm{mg} / \mathrm{kg}$. Nevertheless, few spots of strong contamination are observed. In general, these spots coincide to the localities of the increased zinc content in the substrate. This fact probably follows from an active migration of zinc in the substrate - soil compartment, since one observes an acid medium there. Correlation coefficient of zinc content in substrate vs. that latter in soil is 0.63. Such correlation reveals vertical migration of zinc at the soil profile.

Increased zinc content in precipitates is observed at the watershed of Medvezhii spring and Pletnjazhnaja river, and at the area immediately neighbouring the suburb of the city of Kranoyarsk (see Fig. 4, E). No congruence of the contamination spots is observed among needles, soil and substrate. Two regions exhibit the increased zinc content in vegetation (see Fig. 4, F). The upper reaches of Namourt and Kaltat, and junction area of Sliznevaja Rassokha with Bol'shaja Sliznevja are these regions. It should be noticed, that the areas of increased zinc content in vegetation are not related to the areas of the increased zinc content in substrate and upper soil level. Thus, zinc content in vegetation is related to the content of that former in rock, rather than to other compartments.

\section{Discussion}

Modelling of spatially distributed dynamics of various ecological systems still challenges the experts in various fields ranging from pure mathematics to specific issues in biology and computer science. The variety of approaches is great enough to meet all the aspects of these rather complicated studies. Clear, apparent and powerful modelling of the dynamics of compartments of spatially distributed ecological system is still doubtful, for many reasons. Here we present the results of the modelling of environmental processes running at the discrete and spatially extended ecological system of "Stolby" state reservation. We have implemented the simulation model of the site that figures out some typical steady regimes in the distribution of vegetation over the territory of zapovednik, and distribution of global pollutants affecting the ecosystem. GIS technologies and solutions are the key issues of the modelling implementation. Similar approach is present in [14]. They discuss the model for habitat estimation, where this latter is affected by a number of factors. GIS implementation allows to figure out the effect of spatially distributed factors. Similarly, the modelling of generalized pollution pattern at zapovednik allows to evaluate the habitat conditions in that latter, in general. It should be said, that the studies of the environmental processes with the special emphasis to the reserved territories and reference sites with wild nature ecological pattern of habitation draw the attention of researchers (see, e. g., $[10,11])$. These works present the modelling results of the environmental conditions at Katun State reservation located in Altai, where the impact of relief could hardly be taken into account but the GIS technologies and solutions. 
It is a common fact, that environmental conditions impact the plant community and vegetation pattern of a (complex) ecological system, while the detailed pattern of such correspondence is not clear. The altitude of the vegetation place is the key factor here. We found rather stable and distinctive typical communities with prevalence of different forest species occupying the different altitude zones. Figs. 3 and 4 show this relation between the altitude and forest species occupancy, in detail. Such complexes of dominating species are argued sometimes, while they are found by different researchers, in different climatic and environmental conditions; see, e.g., [10,11] for Siberia, [7] for mountain China region. Quite detailed and smart study of such zone structure of forests is studied and discussed by B.Hörsch [12].

The developed model reveals some statistical relations between all four compartments of the studied ecological system. Relief seems to be the leading factor here. Thus, soil types correlate quite closely to the altitude zones. Four types of soils are roughly identified at zapovednik; the types exhibit the prevalence with the altitude. This is not a point, since the types are mainly identified being based on the altitude zone structure. A relation between the class of soil and the altitude is less obvious. Eight classes of soil are determined at zapovednik; each class preferably occupies a specific altitude belt. A dispersion of the classes among themselves observed at zapovednik results from the highly jagged relief of the reservation.

On the contrary, one sees quite poor correlation between vegetation type, and soil class. One could expect to meet an increased correlation between these two compartments of the ecosystem, while there is observed rather poor correlation between these entities. The point is that soil formation is affected with a number of factors, including relief, rock, climate, season, vegetation, etc. All these factors force the relation simultaneously and, quite often, in opposite directions. Such complex interaction obturates discretion of the effect of a peculiar factor. More close study of the relations between soil class and vegetation reveals a decreased correlation among them. This fact means that the structure of forest associations fails to identify unambiguously the relevant class of soil. Similar observations are discussed in [12].

The efficiency of the approach to the modelling shown above should be used to study the dynamics of various pollutant distributions over an ecosystem. The dynamics of the transfer of such compounds could hardly be taken with the analytical modelling solely. The point is, that the pollutants are transferred both actively, by biotic components of an ecosystem, and passively, through the diffusion and other types of inactive transportation web. Such approach was used in [8], where the smart decision-making support system was implemented for the tasks of forest management and control. The GIS-based modelling is widely used for the studies of the dispersion of contaminations among the compartments of various ecosystems (see, e.g., [13]). The monitoring system supported with various Internet solutions becomes a new interactive scientific tool for a community of experts in various fields; see, e.g. http://info.krasn.ru/stolby/ and http://res.krasu.ru/ses/doc/1_1.shtml or [10]. 
The results of the study presented here are mainly focused on the development of the simulation model describing the dynamics of vegetation and pollutant distribution for the purposes of environmental monitoring at "Stolby" reservation. The most up-to-date methods of cartography modelling and GISbased analysis were used due to implement informational technologies of a complex analysis of spatial geographical data and environmental data. The methodology presented above is currently implemented for the studies of the "Tzentral'nosibirskii" State Biospheric Wildnature Reservation located at the southern part of Turukhansk region of Krasnoyarsk krai, and, partially, at Evenk autochthon area (Baikit region). The area of the reservation is 972017 hectares, exceeding more than 20 times the area of "Stolby" State Reservation. An efficiency of CIS technologies for the purposes of wildnature monitoring is evident; the technologies could be expanded for other territories, which meet a defence by society. A detail study due to GIS-technologies of the state and dynamics of natural processes at the "Tzentral'nosibirskii" State Biospheric Wildnature Reservation reveals the reference pattern of the dynamics of natural processes at the biosphere, since anthropogenic influence on the reservation is very low. The data gathered at the reservation could be used for estimation of the state of any reserved territory, both at Russia, and outside.

\section{References}

1. Erunova M.G. Implementation of geoinformation system of the "Stolby" State reservation // Zapovednoe delo. iss. 9. Moscow, 2001. pp. $76-80$.

2. Iverson, L.R., Dale, M.E., Scott, T., Prasad, A. A GIS-derived integrated moisture index to predict forest composition and productivity of Ohio forests (USA). // Landscape Ecol. 1997. 12, pp.331 - 348.

3. Tappeiner U., Tasser E., Tappeiner G. Modelling vegetation patterns using natural and anthropogenic influence factors: preliminary experience with A GIS based model applied to an Alpine area. // Ecol. Model. 1998. 113, pp.225 - 237.

4. Münier B., Nygaard B., Ejrnæs R., Bruun H.G. A biotope landscape model for prediction of semi-natural vegetation in Denmark. // Ecol. Model. 2001. 139, pp.221 $-233$.

5. Dymond C.C., Johnson E.A. Mapping vegetation spatial patterns from modelled water, temperature and solar radiation gradients. // Photogrammetry Remote Sens. 2002. 57, pp.69-85.

6. Pfeffer K., Pebesma E.J., Burrough P.A. Mapping Alpine vegetation using vegetation observations and topographic attributes. // Landscape Ecol. 2003. 18, pp.759 -776 .

7. Chuanyan Zhao, Zhongren Nan, Guodong Cheng, Junhua Zhang and Zhaodong Feng. GIS-assisted modelling of the spatial distribution of Qinghai spruce (Picea crassifolia) in the Qilian Mountains, northwestern China based on biophysical parameters // Ecological Modelling, In Press, Available online 10 August 2005.

8. Ostwald M. GIS-based support tool system for decision-making regarding local forest protection: illustrations from Orissa, India. // Environ.Management. 2002, Vol.30, \# 1, pp.35 - 45. 
9. Ji W.W., Leberg P. A GIS-based approach for assessing the regional conservation status of genetic diversity: an example from the southern Appalachians. // Environ.Manage. 2002. Vol.29, \# 4, pp.531 - 544.

10. Prechtel N. GIS-Aufbau für den Naturschutz im Russischen Altai. In: Geoinformationssysteme - Theorie, Anwendungen, Problemlösungen. Kartographische Bausteine, Bd. 21, Inst. for Cartography, TU Dresden, 2003a, pp. 82 - 100.

11. Prechtel N. Selected Problems and Solutions for Drainage Modelling and Handling in a GIS. In: Geoinformationssysteme - Theorie, Anwendungen, Problemlösungen. Kartographische Bausteine, Bd. 21, 2003b. Inst. für Kartographie, TU Dresden, pp.101 - 109 .

12. Hörsch B. Modelling the spatial distribution of montane and subalpine forests in the central Alps using digital elevation models // Ecological Modelling, 2003, 168(3) pp.267 - 282.

13. Siu-lan Lee C., Xiangdong Li, Wenzhong Shi, Ching-nga Cheung Sh., Thornton I. Metal contamination in urban, suburban, and country park soils of Hong Kong: A study based on GIS and multivariate statistics / Science of the Total Environment, 2006, vol.356(1-3), pp.45-61.

14. Store R., Jokimäki J. A GIS-based multi-scale approach to habitat suitability modelling // Ecological Modelling, vol.169, Iss. 1, 2003, pp.1 - 15.

15. Erunova M.G., Yakubailik O.E., Kadachnikov A.A. Geoinformation analysis of nature condition at "Stolby" reservatioin // Geography and natural resources. 2006, \# 2; pp. 136 - 142 .

16. Erunova M.G., Gosteva A.A., Yakubailik O.E. GIS support for the environmental monitoring of wildnature reservations // SFU Journal, ser. Technics and technology. 2008, v. 1, \# 4, pp.366 - 376.

17. Erunova M.G., Sadovsky M.G., Gosteva A.A. GIS-aided simulation of spatially distributed environmental processes at "Stolby" state reservation // Ecological Modelling. 2006. v. 195. \# 3-4. pp.296 - 306.

18. Gavrikov V.L., Sharafutdinov R.A., Knorre A.A., Pakharkova N.V., Shabalina O.M., Bezkorovaynaya I.N., Borisova I.V., Erunova M.G., Khlebopros R.G. How much carbon can the Siberian boreal taiga store: a case study of partitioning among the above-ground and soil pools. Journal of Forestry Research. 2016. V. 27, \# 4, pp. $907-912$. 